\title{
Effect Size of Dietary Supplementation and Physical Exercise Interventions for Sarcopenia in Middle-Aged Women
}

\author{
Ji-Min Park', Young-Ho Kim², So-Young Lee, and Ae-Jung Kim ${ }^{4}$ \\ ${ }^{1}$ Department of Alternative Medicine, Kyonggi University, Seoul 03752, Korea \\ ${ }^{2}$ Department of Baking Science \& Technology, Hyejeon College, Chungnam 32244, Korea \\ ${ }^{3}$ Department of Medium Therapy and ${ }^{4}$ Department of Nutrition Therapy, The Graduate School of Alternative Medicine, \\ Kyonggi University, Seoul 03752, Korea
}

\begin{abstract}
The purpose of this meta-analysis was to comprehensively analyze the relationship between intervention (dietary supplementation and physical exercise), body composition, and physical activity capacity in middle-aged women with sarcopenia. A total of 19 studies published in the last ten years were selected. The overall effect size was small $(0.29 ; 95 \%$ confidence interval: $0.195 \sim 0.385$ ). The Q value was 100.214 and the Higgin's $I^{2}$ value was 82.038 . Each study was found to be heterogeneous and there was no publication bias. The effect size was increased when the number of study participants increased from 50 to 100 and when dietary vitamin D supplementation was combined with resistance exercise. Furthermore, the effect on physical activity capacity was higher than that on body composition. In conclusion, dietary vitamin D supplementation combined with resistance training had a positive impact on middle-aged women with sarcopenia.
\end{abstract}

Keywords: dietary supplementation, meta-analysis, middle-aged, physical exercise, sarcopenia

\section{INTRODUCTION}

The number of elderly people is increasing rapidly worldwide (United Nations, 2019). According to the World Population Prospects 2019 released by the United Nations, the percentage of senior citizens aged 60 or older increased from $9.9 \%$ in 2000 to $13.5 \%$ in 2020 , with $14.6 \%$ female senior citizens in 2020 . In Korea, the population of senior citizens aged 60 or older is expected to increase very rapidly, with estimated populations of 30.8 billion in 2000, 65.2 billion in 2020, and 112.8 billion in 2050 (United Nations, 2019).

Degenerated diseases such as sarcopenia are increasing due to the rapidly increasing number of elderly people (Hong and Choi, 2012). Globally, the percentage of elderly people aged 60 and over with sarcopenia is estimated to be $10 \%$ (Pacifico et al., 2020). Depending on diagnostic criteria, pathological conditions, and gender, this percentage can be as high as $50 \%$ (Papadopoulou, 2020). The prevalence rate of sarcopenia in Korean adults is $17.7 \%$ for women aged 20 to 39 years, $30.8 \%$ for those aged 40 to 64 years, and $41.8 \%$ for those aged 65 years and older (Bae and Kim, 2017).
Sarcopenia is a compound word (Rosenberg, 1989) comprising 'sarx', which means muscle, and 'penia', which means reduction. Rosenberg (1989) first introduced the concept of 'sarcopenia'. Initially, muscle function was simply defined as bone muscle mass. However, since 2010, the term sarcopenia has been used to describe reduced muscle mass and muscle strength due to aging (Rosenberg, 2011).

There are several mechanisms involved in the occurrence of sarcopenia. Typical factors include an imbalance of nutrition and decreased muscle mass (Hughes et al., 2002; Calvani et al., 2014), hormonal imbalance due to aging (Urban, 2011), and inflammatory phenomena (Peake et al., 2010). However, sarcopenia is more than a simple change in muscle mass (Di Monaco et al., 2011; Visser and Schaap, 2011). Sarcopenia can cause a variety of health problems such as decreased physical activity (da Silva Alexandre et al., 2014), high blood pressure (Han et al., 2014), metabolic syndrome (Lim et al., 2010), frailty (Morley et al., 2014), cardiovascular disease (Bae and Kim, 2016), and increased mortality (Batsis and Villareal, 2018). Therefore, it is necessary to prevent sarcopenia from middle age, which is the pre-stage of being elderly in 
the life cycle, through physical exercise and dietary supplementation (The Korean Society of Sarcopenia, 2017), both common interventions for sarcopenia without depending on drugs. Prevention of sarcopenia starting in middle age can ultimately affect quality of life of the elderly (Öztürk et al., 2018).

Most domestic and international meta-analyses related to sarcopenia have only calculated the effect size of interventions for sarcopenia of people aged 65 or older. To date, no meta-analyses have investigated the effect size of interventions on sarcopenia in middle-aged women. Therefore, the purpose of this study was to perform a meta-analysis to comprehensively analyze the relationship between interventions, body composition and physical activity capacity based on studies published in the past 10 years (2009 to 2019). In total, 19 studies reporting effective physical exercise and dietary supplementation interventions for sarcopenia in middle-aged women were selected.

\section{MATERIALS AND METHODS}

\section{Search strategy and selection methods}

The following search engines were used for a systematic search: Research Information Sharing Service (RISS), National Digital Science Library (NDSL), National Assembly Library (NAL), and National Center for Medical Information and Knowledge (NCMIK) for the Korean databases; Cochrane Library and PubMed (MEDLINE) for the international databases. The following terms were used as search terms: 'sarcopenia', 'middle-aged', and 'women'. Studies were included if they met the following criteria: 1) published in the last 10 years from January 2009 to July $2019 ; 2$ ) related to the effect of physical exercise and dietary supplementation on sarcopenia; 3) participants were middle-aged women aged under 65 years; 4) studies that provided mean and standard deviation (SD) for each group used for comparison. Exclusion criteria were: 1) studies that combined results of middle-aged with senescence, or men and women; 2) studies that used drugs or hormones for intervention. To improve the accuracy of the search, three Ph.D. students, including the researcher, conducted three or more searches for each search term.

\section{Characteristics of selected studies}

In this study, the sizes of the effects of interventions on body composition and physical activity capacity were analyzed according to the study design method, study period, number of subjects, and intervention types. First, 'study design' and 'study period' were considered for the meta-analysis. 'Study design' was divided into 'unmatched group pre-post' and 'one group pre-post'. 'Study period' was based on 15 weeks, divided into before and after. All participants were middle-aged women aged under 65 years old. The 'number of subjects' was divided to 50 . However, because the total number of subjects in studies and the number of people actually divided did not coincide, the analysis for the number of study subjects was conducted based on the number of participants in the group, not the total number. Third, the 'type of intervention' was divided into dietary supplementation and physical exercise and the 'form of intervention' was classified as either single and combined. For dietary supplementation, effect sizes for vitamin D and protein were analyzed. For physical exercise, effect sizes for aerobic exercise and resistance training were analyzed.

\section{Quality assessment}

Quality assessment was used to eliminate or minimize the possibility of bias (Lim et al., 2011). The Cochrane tool for evaluating prospective randomized controlled double-blind clinical trials (Lim et al., 2011) was used.

Measurements and interpretation of intervention effect size Effect size refers to a standardized scale by a standardization process that changes results on individual scales to the same scale. Effect size was measured to examine estimates using standardized mean differences of D family, as presented by Cohen (1988), and 95\% confidence interval.

\section{Statistical analysis}

The meta-analysis was performed using the comprehensive meta-analysis version 3 program developed by Biostat in the USA in 1986. For heterogeneity analysis, we applied visual plots such as forest plot, Q statistics and Higgin's $I^{2}$ statistics. Due to different characteristics of the included studies, random effect models were selected to calculate pooled effect measures. As a method of examining publication bias, the funnel plot method and trim-and-fill (Duval and Tweedie, 2000) technique were used to compare observed values.

\section{RESULTS AND DISCUSSION}

\section{Selection and inclusion of studies}

When conducting the systematic search, we identified 1,552 relevant studies in the Cochrane Library, PubMed, RISS, NDSL, NAL, and NCMIK databases. A total of 669 studies remained after duplicates were removed, of which 621 were excluded after initial screening of the title and abstract. Full texts of the remaining 48 studies were reviewed in detail, and 29 were excluded due to no follow up, no dietary supplementation or exercise intervention, different age cohorts, or no information for mean and SD. The procedure used for searching and selecting studies 


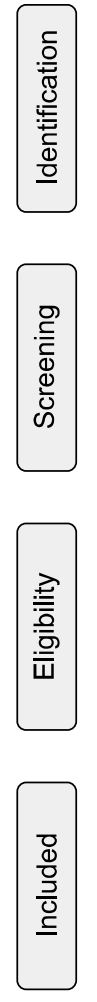

Records identified through Cochrane Library (57),

PubMed (548), RISS (19), NDSL (28),

NAL (5), NCMIK (895) database searching

$(n=1,552)$
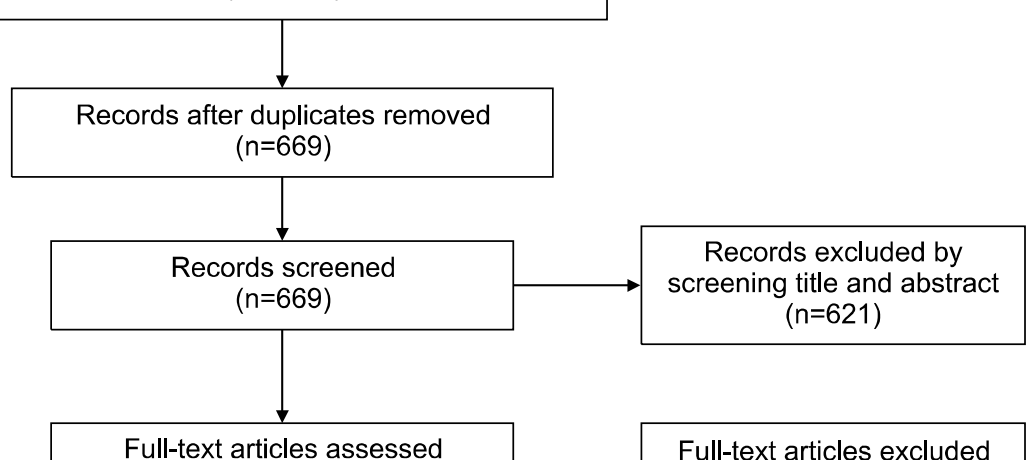

Full-text articles excluded $(n=29)$

Main reasons were: doesn't have follow-up, not supplementary or exercise intervention, different age cohorts missing mean and SD
Fig. 1. PRISMA flow chart for the literature searching strategy and procedure for study selection. PRISMA preferred reporting items for systematic reviews and meta-analysis; RISS, Research Information Sharing Service; NDSL, National Digital Science Library; NAL, National Assembly Library; NCMIK, National Center for Medical Information and Knowledge; SD, standard deviation. according to the preferred reporting items for systematic reviews and meta-analysis flow (PRISMA) diagram is presented in Fig. 1. A total of 19 research studies (4 domestic and 15 foreign studies) satisfying the population, intervention, comparison, outcome, study design (PICOS) criteria were selected for inclusion in the meta-analysis.

\section{Characteristics of the selected studies}

Characteristics of the studies included in the meta-analysis are shown in Table 1 . The 19 selected studies were published from 2009 to 2019 (over the last 10 years), and were conducted in the following countries: USA $(n=1)$, Brazil $(n=4)$, South Korea $(n=4)$, Taiwan $(n=1)$, Thai-

Table 1. Characteristics of the studies included in the meta-analysis $(n=19)$

\begin{tabular}{|c|c|c|c|c|c|c|}
\hline Reference & Publication & Country & Age (yr) & $\mathrm{N}$ & Intervention & $\begin{array}{c}\text { Study } \\
\text { duration }\end{array}$ \\
\hline Cangussu et al. (2015) & Osteopros Int & Brazil & $59.05 \pm 6.65$ & 160 & Vitamin D & 9 mon \\
\hline Mason et al. (2013) & Med Sci Sports Exerc & USA & $57.92 \pm 5$ & 439 & Low calorie diet+aerobic & 12 mon \\
\hline Hsu et al. (2015) & Geriatr Gerontol Int & Taiwan & $62.77 \pm 7.48$ & 154 & Circuit exercise, Tai Chi & 12 wk \\
\hline Francis et al. (2017) & Biogerontology & UK & $61.09 \pm 5.09$ & 57 & Protein+resistance training & $12 \mathrm{wk}$ \\
\hline Hamaguchi et al. (2017) & BMC Geriatr & Japan & $60.51 \pm 2.49$ & 15 & Power training & 6 wk \\
\hline Sammarco et al. (2017) & Obes Facts & Italy & $55 \pm 9.6$ & 18 & Protein & 4 mon \\
\hline Hojan et al. (2013) & Eur J Phys Rehabil Med & Poland & $44.3 \pm 4.9$ & 41 & Aerobic, resistance training & 18 mon \\
\hline Nunes et al. (2016) & Age (Dordr) & Brazil & $60.91 \pm 6.16$ & 32 & Resistance training & 16 wk \\
\hline Nabuco et al. (2018) & Nutrients & Brazil & $\geq 60$ & 66 & $\begin{array}{l}\text { Hydrolyzed whey protein+ } \\
\text { resistance training }\end{array}$ & 12 wk \\
\hline Orsatti et al. (2018) & J Diet Suppl & Brazil & $57.8 \pm 7.83$ & 32 & $\begin{array}{l}\text { Soy protein+ } \\
\text { resistance training }\end{array}$ & $16 \mathrm{wk}$ \\
\hline Iolascon et al. (2017) & Adv & Ita & 68. & 113 & Calcifediol & 6 mon \\
\hline Cho and Jang (2018) & Korean J Sport & Korea & $45.35 \pm 4.95$ & 45 & Rope training & 12 wk \\
\hline Ring-Dimitriou et al. (2009) & Eur J Appl Physiol & Austria & $50.32 \pm 3.04$ & 42 & Resistance training & $12 \mathrm{wk}$ \\
\hline Oh et al. (2018) & JKSLES & Korea & $39 \pm 2.61$ & 13 & Twisting training & $8 w k$ \\
\hline Moslehi et al. (2013) & BiolTrace Elem Res & Iran & $46.3 \pm 4.21$ & 69 & Magnesium & $8 w k$ \\
\hline Abiri et al. (2016) & Nutr Food Sci Res & Iran & $45.47 \pm 2.86$ & 71 & Vitamin D & 12 wk \\
\hline Choi (2018) & Kyungsung University & Korea & $59.58 \pm 4.51$ & 41 & $\begin{array}{l}\text { Gamma-aminobutyric acid+ } \\
\text { resistance training }\end{array}$ & $12 \mathrm{wk}$ \\
\hline Suebthawinkul et al. (2018) & Climacteric & Thailand & $55 \pm 3.16$ & 88 & Vitamin D & $12 w k$ \\
\hline Lee (2017) & JKOEN & Korea & $52.05 \pm 3.71$ & 24 & Circuit training & $12 \mathrm{wk}$ \\
\hline
\end{tabular}

$\mathrm{N}$, number of participant. 
land $(n=1)$, Japan $(n=1)$, Iran $(n=2)$, Italy $(n=2)$, Poland $(n=1)$, UK $(n=1)$, and Austria $(n=1)$. The number of participants varied from 13 to 439, with a total of approximately 1,520 participants. The follow-up study period varied from 6 weeks to 18 months. Intervention factors included vitamin $\mathrm{D}$, vitamin $\mathrm{D}_{3}$, protein, whey protein, soy protein, gamma-aminobutyric acid, magnesium, calcifediol, and low-calorie diet dietary intervention. Physical exercise included aerobic, circuit exercise, Tai Chi, resistance training, power training, rope training, and twisting training.

\section{Heterogeneity tests and overall effect sizes}

Results and forest plots of the 19 included studies are shown in Table 2 and Fig. 2. A total of 152 effect sizes were derived. For homogeneity testing, $\mathrm{Q}$ tests at a significance level of 0.001 confirmed that the overall $Q$ value was not homogeneous at 100.214 , with the value of Higgin's $I^{2}$ for heterogeneity was high at 82.038 . Therefore, a random effect model was selected and used for analysis. Using the random effect model, the overall effect size was 0.290 , which appeared to be less effective numerically. However, considering a gradual loss of muscle with aging (Hughes et al., 2002), the overall effect size was significant because it had a positive effect with the potential to prevent the occurrence of sarcopenia in middle-aged women. One study on the effect size of interventions for sarcopenia in the elderly (Lee and Kim, 2020) reported a higher overall effect than the present study. This may be because sarcopenia is not generally serious in middle age and that the prevalence of sarcopenia is higher in old age (Bae and Kim, 2017), leading to a more pronounced effect on the elderly.

\section{Publication bias}

To explore the validity of this study, we examined publication bias of individual effect sizes through a funnel plot (Fig. 3). From the funnel plot, we determined the distribution of the effect size to be symmetrical overall. However, checking publication bias through the funnel plot could be subjective depending on the researcher, which might hinder the validity of the research. For a more accurate analysis, the trim-and-fill technique (Duval and Tweedie, 2000) as a method for confirming publication bias was additionally used. As shown in Fig. 3 and Table 2 , there was no change in the estimated value (Fig. 3A)

Table 2. Overall intervention effect sizes of sarcopenia including Duval and Tweedie's trim and fill test results

\begin{tabular}{cccccccc}
\hline Value & $\mathrm{K}$ & $\begin{array}{c}\text { Studies } \\
\text { trimmed }\end{array}$ & $\begin{array}{c}\text { Point } \\
\text { estimate }\end{array}$ & $95 \% \mathrm{CI}$ & $\mathrm{Q}$ & $P$-value & $I^{2}$ \\
\hline Observed value & 19 & - & 0.290 & $0.195 \sim 0.385$ & 100.214 & $P<0.001$ & 82.038 \\
Adjusted value & 19 & 0 & 0.290 & $0.195 \sim 0.385$ & 100.214 & $P<0.001$ & 82.038 \\
\hline
\end{tabular}

Data from the article of Duval and Tweedie (2000).

$\mathrm{K}$, number of studies; CI, confidence interval; $\mathrm{Q}, \mathrm{Q}$ statistics; $I^{2}$, Higgin's $I^{2}$ statistics.

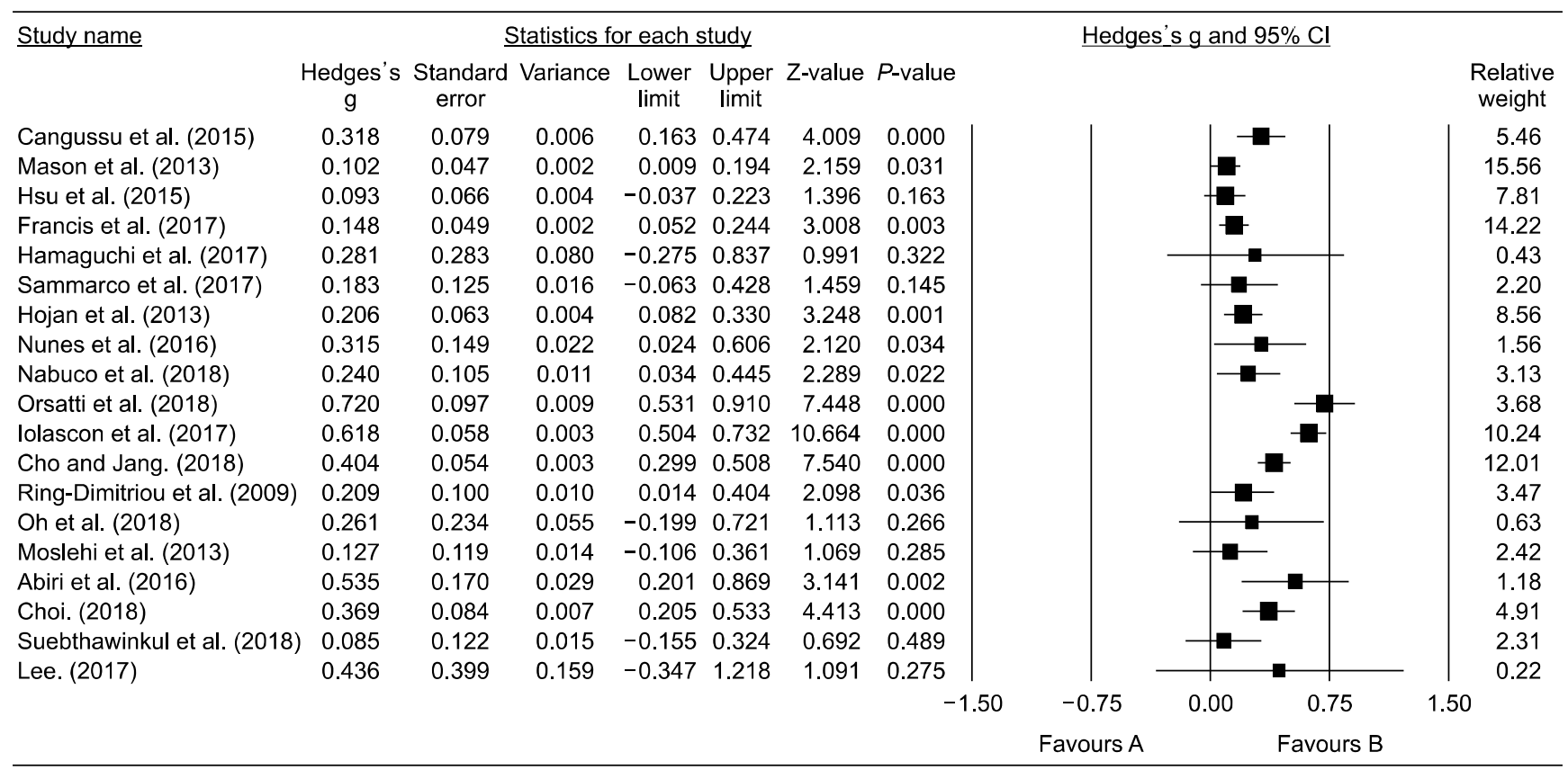

Fig. 2. Forest plot for the overall interventions of the 19 selected studies. 
A

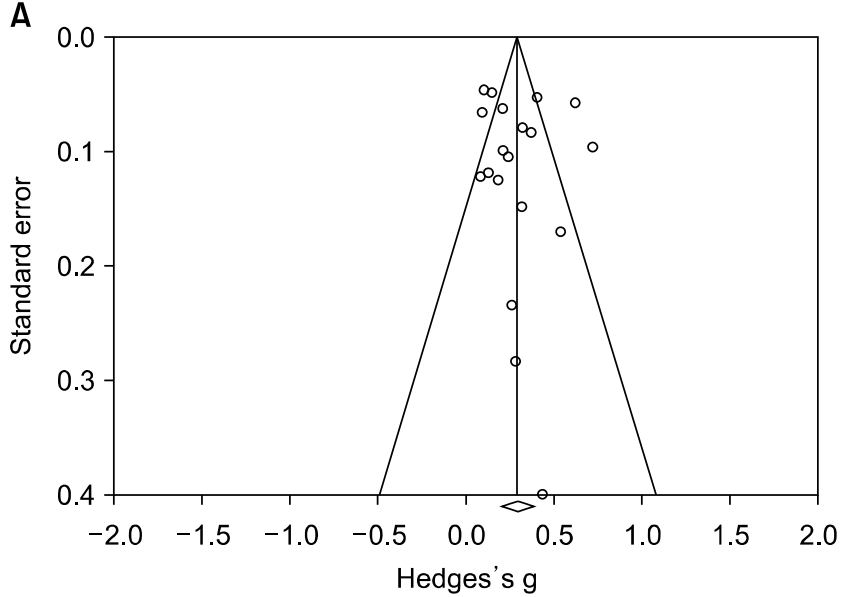

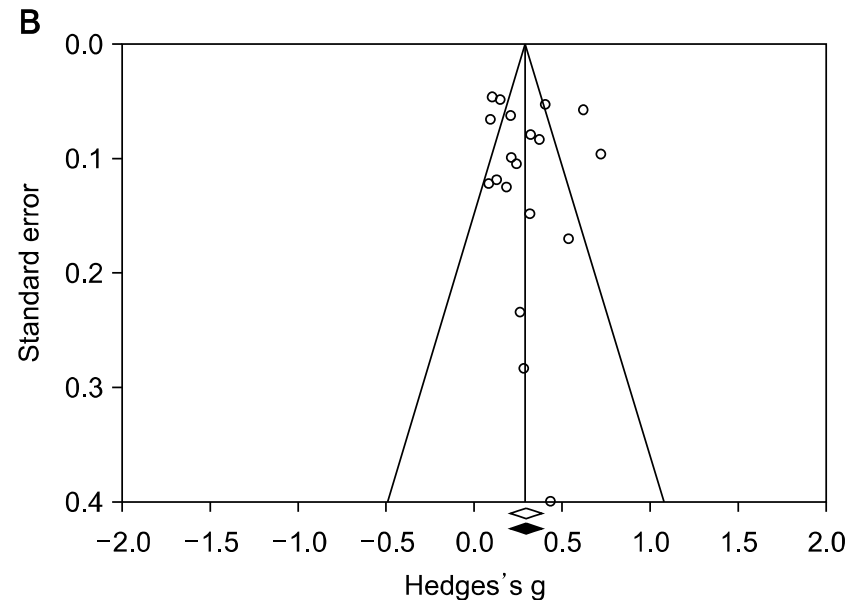

B

Hedges's $g$

Fig. 3. (A) Funnel plot for the evaluation of publication bias of sarcopenia: observed values. (B) Funnel plot for the evaluation of publication bias of sarcopenia: adjusted values.

or adjusted value (Fig. 3B) after the indicated correction, indicating no publication bias. Thus, the validity of this study was confirmed.
Intervention effect size by the designs of the included studies

The study designs were classified into an unmatched

Table 3. Effect sizes on sarcopenia by study parameter

\begin{tabular}{|c|c|c|c|c|c|c|c|}
\hline \multicolumn{3}{|c|}{ Factor } & K & ES & $95 \% \mathrm{CI}$ & Q & $P$-value \\
\hline \multicolumn{3}{|l|}{ All } & 19 & 0.290 & $0.195 \sim 0.385$ & 100.214 & $P<0.001$ \\
\hline \multicolumn{8}{|l|}{ Study method } \\
\hline \multirow{2}{*}{ Study design } & \multicolumn{2}{|c|}{ Unmatched group pre-post } & 80 & 0.191 & $0.138 \sim 0.245$ & 51.208 & $P<0.001$ \\
\hline & \multicolumn{2}{|c|}{ One group pre-post } & 72 & 0.343 & $0.272 \sim 0.414$ & 132.298 & $P<0.001$ \\
\hline \multirow[t]{2}{*}{ Study period } & \multicolumn{2}{|l|}{ Before $15 \mathrm{wk}$} & 107 & 0.238 & $0.188 \sim 0.288$ & 95.872 & $P<0.001$ \\
\hline & \multicolumn{2}{|l|}{ After 15 wk } & 45 & 0.325 & $0.238 \sim 0.412$ & 100.600 & $P<0.001$ \\
\hline \multicolumn{8}{|c|}{ Study subject (no) } \\
\hline \multirow[t]{3}{*}{ Participant } & \multirow{3}{*}{\multicolumn{2}{|c|}{$\begin{array}{l}1 \leq \text { to }<50 \\
50 \leq \text { to }<100 \\
\geq 100\end{array}$}} & 130 & 0.272 & $0.226 \sim 0.318$ & 132.602 & $P<0.001$ \\
\hline & & & 11 & 0.306 & $0.134 \sim 0.478$ & 28.121 & $P<0.001$ \\
\hline & & & 11 & 0.202 & $0.051 \sim 0.353$ & 37.502 & $P<0.001$ \\
\hline \multicolumn{8}{|c|}{ Intervention form } \\
\hline \multirow{6}{*}{$\begin{array}{l}\text { Single } \\
\text { intervention }\end{array}$} & \multirow{3}{*}{$\begin{array}{l}\text { Dietary } \\
\text { supplementation }\end{array}$} & Total & 42 & 0.262 & $0.179 \sim 0.345$ & 76.333 & $P<0.001$ \\
\hline & & Vitamin D & 14 & 0.416 & $0.269 \sim 0.563$ & 38.022 & $P<0.001$ \\
\hline & & Protein & 21 & 0.138 & $0.035 \sim 0.241$ & 8.032 & $P<0.01$ \\
\hline & \multirow[t]{3}{*}{ Physical exercise } & Total & 72 & 0.247 & $0.185 \sim 0.310$ & 75.814 & $P<0.001$ \\
\hline & & Aerobic exercise & 16 & 0.096 & $-0.004 \sim 0.196$ & 2.470 & $P<0.1$ \\
\hline & & $\begin{array}{l}\text { Resistance } \\
\text { training }\end{array}$ & 50 & 0.354 & $0.262 \sim 0.445$ & 55.262 & $P<0.001$ \\
\hline \multirow{2}{*}{\multicolumn{3}{|c|}{$\begin{array}{l}\text { Combined intervention } \\
\text { Anthropometric measurements }\end{array}$}} & 38 & 0.329 & $0.225 \sim 0.433$ & 55.691 & $P<0.001$ \\
\hline & & & & & & & \\
\hline \multirow{5}{*}{$\begin{array}{l}\text { Body } \\
\text { composition }\end{array}$} & Total & & 80 & 0.162 & $0.114 \sim 0.211$ & 33.072 & $P<0.001$ \\
\hline & \multirow{3}{*}{$\begin{array}{l}\text { Single } \\
\text { intervention }\end{array}$} & Total & 61 & 0.153 & $0.098 \sim 0.207$ & 19.351 & $P<0.001$ \\
\hline & & $\begin{array}{l}\text { Dietary } \\
\text { supplementation }\end{array}$ & 16 & 0.164 & $0.070 \sim 0.258$ & 3.904 & $P \leq 0.001$ \\
\hline & & Physical exercise & 45 & 0.147 & $0.080 \sim 0.213$ & 15.357 & $P<0.001$ \\
\hline & $\begin{array}{l}\text { Combined } \\
\text { intervention }\end{array}$ & & 19 & 0.201 & $0.093 \sim 0.309$ & 13.114 & $P<0.001$ \\
\hline \multirow{5}{*}{$\begin{array}{l}\text { Capacity of } \\
\text { physical } \\
\text { activity }\end{array}$} & Total & & 72 & 0.412 & $0.335 \sim 0.488$ & 120.997 & $P<0.001$ \\
\hline & \multirow{3}{*}{$\begin{array}{l}\text { Single } \\
\text { intervention }\end{array}$} & Total & 53 & 0.400 & $0.310 \sim 0.489$ & 93.263 & $P<0.001$ \\
\hline & & $\begin{array}{l}\text { Dietary } \\
\text { supplementation }\end{array}$ & 26 & 0.321 & $0.201 \sim 0.441$ & 58.412 & $P<0.001$ \\
\hline & & Physical exercise & 27 & 0.510 & $0.380 \sim 0.640$ & 32.089 & $P<0.001$ \\
\hline & $\begin{array}{l}\text { Combined } \\
\text { intervention }\end{array}$ & & 19 & 0.449 & $0.296 \sim 0.601$ & 27.732 & $P<0.001$ \\
\hline
\end{tabular}

$\mathrm{K}$, number of studies; $\mathrm{ES}$, effect size (point estimate); $\mathrm{CI}$, confidence interval; $\mathrm{Q}, \mathrm{Q}$ statistics. 
group pre-post and one group pre-post group. Differences and the significances of the effect sizes according to the duration of the study period were divided into before and after 15 weeks. The effect sizes are shown in Table 3.

The effect size of the unmatched group pre-post was 0.191 , and the effect size of the one group pre-post was 0.343 , thus it was more effective to experiment with one group. From reviewing 7 studies, vitamin D and resistance exercise, which were used as interventions in six studies, were found to have high effect sizes. In addition, 4 of 7 studies were conducted over a period of at least 15 weeks and were found to have high effect sizes. Thus, it can be predicted that the effect size of studies conducted on a single group is higher. From analyzing the effect size according to the study period, the effect size was 0.238 when the study period was less than 15 weeks and 0.325 when the study period was more than 15 weeks.

\section{Intervention effect size according to the study subjects}

The number of study subjects and the countries in which they were conducted are shown in Table 3 . The number of study subjects was classified as either less than 50,50 to 100 , or 100 or more. The effect size was 0.272 for less than 50 subjects, 0.306 for 50 to 100 subjects, and 0.202 for more than 100 subjects. Although only 11 studies had 50 to 100 subjects, the highest effect size was shown for these studies. Therefore, 50 to 100 subjects would be suitable for efficient management and control.

\section{Intervention effect size according to the type and form of the intervention method}

Effect sizes according to the type and form of the interventions are presented in Table 3. Single intervention was classified as dietary supplementation or physical exercise. Supplemental dietary factors included vitamin D and protein, and physical exercise factors included aerobic and resistance training.

The effect size for a single intervention of supplemental dietary factors was 0.262 . The effect sizes of vitamin $\mathrm{D}$ and protein were 0.416 and 0.138 , respectively. Effect sizes for a single intervention of total physical exercise, aerobic exercise, and resistance exercise were 0.247 , 0.096 , and 0.354 , respectively. The effect size of both dietary supplementation and physical exercise was 0.329 , larger than that of either intervention alone. This was consistent with findings by Hita-Contreras et al. (2018), who reported greater effect sizes for simultaneous interventions compared with single interventions.

When effect sizes were comprehensively compared, the largest effect sizes were shown for vitamin D consumption (dietary supplementation) and resistance training (physical exercise). Also, effect sizes were greater when dietary supplementation and physical exercise interventions were combined in parallel than with a single inter- vention. Therefore, when developing programs to prevent or improve sarcopenia for middle-aged women, vitamin $\mathrm{D}$ rich food intake and resistance training should be included.

\section{Intervention effect sizes based on anthropometric meas- urements}

We also performed subgroup analysis based on anthropometric measurements (body composition and capacity of physical activity) (Table 3). In this study, capacity of physical activity had a higher effect size (0.412) than body composition (0.162), indicating that it is more effective to improve physical activity capacity than body composition. Thus, physical activity capacity rather than body composition can be improved in sarcopenia since dietary supplementation and physical exercise interventions could have a positive effect on muscle function.

To examine the relationship between anthropometric measurements (body composition and physical activity capacity) and intervention type, a sub-analysis was conducted. In most cases, the effect size was higher for combined interventions than for single interventions.

The effect size of body composition was 0.201 for combined interventions, 0.164 for a single dietary supplementation intervention, and 0.147 for a single physical exercise intervention. The effect size of physical activity capacity was 0.510 for a single physical exercise intervention, 0.449 for combined interventions, and 0.321 for a single dietary supplementation intervention. The effect size analysis showed that physical exercise was more effective than dietary supplementation to improve physical performance.

In this study, a meta-analysis was conducted to determine the effectiveness of dietary supplementation and physical exercise for sarcopenia in middle-aged women based on studies published in the past 10 years. The overall effect size of sarcopenia in middle-aged women was 0.290 .

From comparing study characteristics and effect of each intervention variable, the effect size was found to be greater if the study design was a one group pre-post, the study period was 15 weeks or longer, and the study had 50 to 100 subjects. In addition, dietary supplementation was better than physical exercise, and combined interventions were better than single interventions.

Based on the results from this study, when developing a program for preventing or improving sarcopenia for middle-aged women, resistance exercise in addition to vitamin D supplementation should be considered. From analyzing the effect sizes of the interventions for sarcopenia on anthropometric measurements, the effect sizes for physical activity capacity was higher than for body composition. Thus, a combination of dietary supplementation and exercise therapy could improve physical activ- 
ity capacity more than dietary supplementation or exercise intervention alone.

\section{AUTHOR DISCLOSURE STATEMENT}

The authors declare no conflict of interest.

\section{REFERENCES}

Abiri B, Vafa MR, Dehghani M, Moslehi N, Sarrafzadeh J. Effect of vitamin D supplement consumption on muscle strength, muscle function and body composition in vitamin D-deficient middle-aged women: a randomized clinical trial. Nutr Food Sci Res. 2016. 3:17-24.

Bae EJ, Kim YH. Association between sarcopenia and cardiovascular disease: based on Korea National Health and Nutrition Examination Survey (KNHANES) 2008-2011. JKDAS. 2016. 18:2961-2974.

Bae EJ, Kim YH. Factors affecting sarcopenia in Korean adults by age groups. Osong Public Health Res Perspect. 2017. 8:169178.

Batsis JA, Villareal DT. Sarcopenic obesity in older adults: aetiology, epidemiology and treatment strategies. Nat Rev Endocrinol. 2018. 14:513-537.

Calvani R, Martone AM, Marzetti E, Onder G, Savera G, Lorenzi $\mathrm{M}$, et al. Pre-hospital dietary intake correlates with muscle mass at the time of fracture in older hip-fractured patients. Front Aging Neurosci. 2014. 6:269. https://doi.org/10.3389/fnagi. 2014.00269

Cangussu LM, Nahas-Neto J, Orsatti CL, Bueloni-Dias FN, Nahas EA. Effect of vitamin D supplementation alone on muscle function in postmenopausal women: a randomized, double-blind, placebo-controlled clinical trial. Osteoporos Int. 2015. 26:24132421.

Cho JY, Jang WS. The effect of battle rope interval training by exercise intensity on body composition, basal physical fitness in middle aged women. Korean J Sport. 2018. 16:581-592.

Choi WC. Effects of combined exercise and GABA intake on sarcopenia and locomotive syndrome in middle-aged women. Dissertation. Kyungsung University, Busan, Korea. 2018.

Cohen J. Statistical power analysis for the behavioral sciences. 2nd ed. Routledge, New York, NY, USA. 1988. p 8-13.

da Silva Alexandre T, de Oliveira Duarte YA, Ferreira Santos JL, Wong R, Lebrão ML. Sarcopenia according to the European working group on sarcopenia in older people (EWGSOP) versus dynapenia as a risk factor for disability in the elderly. J Nutr Health Aging. 2014. 18:547-553.

Di Monaco M, Vallero F, Di Monaco R, Tappero R. Prevalence of sarcopenia and its association with osteoporosis in 313 older women following a hip fracture. Arch Gerontol Geriatr. 2011. 52:71-74.

Duval S, Tweedie R. Trim and fill: a simple funnel-plot-based method of testing and adjusting for publication bias in metaanalysis. Biometrics. 2000. 56:455-463.

Francis P, Mc Cormack W, Toomey C, Norton C, Saunders J, Kerin E, et al. Twelve weeks' progressive resistance training combined with protein supplementation beyond habitual intakes increases upper leg lean tissue mass, muscle strength and extended gait speed in healthy older women. Biogerontology. 2017. 18:881-891.

Hamaguchi K, Kurihara T, Fujimoto M, Iemitsu M, Sato K, Hamaoka T, et al. The effects of low-repetition and light-load power training on bone mineral density in postmenopausal women with sarcopenia: a pilot study. BMC Geriatr. 2017. 17:102. https://doi.org/10.1186/s12877-017-0490-8

Han K, Park YM, Kwon HS, Ko SH, Lee SH, Yim HW, et al. Sarcopenia as a determinant of blood pressure in older Koreans: findings from the Korea National Health and Nutrition Examination Surveys (KNHANES) 2008-2010. PLoS One. 2014. 9:e86902. https://doi.org/10.1371/journal.pone.0086902

Hita-Contreras F, Bueno-Notivol J, Martínez-Amat A, Cruz-Díaz D, Hernandez AV, Pérez-López FR. Effect of exercise alone or combined with dietary supplements on anthropometric and physical performance measures in community-dwelling elderly people with sarcopenic obesity: a meta-analysis of randomized controlled trials. Maturitas. 2018. 116:24-35.

Hojan K, Milecki P, Molińska-Glura M, Roszak A, Leszczyński P. Effect of physical activity on bone strength and body composition in breast cancer premenopausal women during endocrine therapy. Eur J Phys Rehabil Med. 2013. 49:331-339.

Hong S, Choi WH. Clinical and physiopathological mechanism of sarcopenia. Korean J Med. 2012. 83:444-454.

Hsu WH, Hsu RW, Lin ZR, Fan CH. Effects of circuit exercise and Tai Chi on body composition in middle-aged and older women. Geriatr Gerontol Int. 2015. 15:282-288.

Hughes VA, Frontera WR, Roubenoff R, Evans WJ, Singh MA. Longitudinal changes in body composition in older men and women: role of body weight change and physical activity. Am J Clin Nutr. 2002. 76:473-481.

Iolascon G, Moretti A, de Sire A, Calafiore D, Gimigliano F. Effectiveness of calcifediol in improving muscle function in postmenopausal women: a prospective cohort study. Adv Ther. 2017. 34:744-752.

Lee HB. Impact of circuit training on mid-aged women's quality of life improvement. JKOEN. 2017. 11:89-97.

Lee HJ, Kim AJ. A meta-analysis on the effect size of physical activity, nutrition and health education-related intervention for sarcopenia in the elderly. KJGSW. 2020. 75:65-97.

Lim S, Kim JH, Yoon JW, Kang SM, Choi SH, Park YJ, et al. Sarcopenic obesity: prevalence and association with metabolic syndrome in the Korean Longitudinal Study on Health and Aging (KLoSHA). Diabetes Care. 2010. 33:1652-1654.

Lim SM, Shin ES, Lee SH, Seo KH, Jung YM, Jang JE. Tools for assessing quality and risk of bias by levels of evidence. J Korean Med Assoc. 2011. 54:419-429.

Mason C, Xiao L, Imayama I, Duggan CR, Foster-Schubert KE, Kong A, et al. Influence of diet, exercise, and serum vitamin D on sarcopenia in postmenopausal women. Med Sci Sports Exerc. 2013. 45:607-614.

Morley JE, Anker SD, von Haehling S. Prevalence, incidence, and clinical impact of sarcopenia: facts, numbers, and epidemiology - update 2014. J Cachexia Sarcopenia Muscle. 2014. 5:253259.

Moslehi N, Vafa M, Sarrafzadeh J, Rahimi-Foroushani A. Does magnesium supplementation improve body composition and muscle strength in middle-aged overweight women? A doubleblind, placebo-controlled, randomized clinical trial. Biol Trace Elem Res. 2013. 153:111-118.

Nabuco HCG, Tomeleri CM, Sugihara Junior P, Fernandes RR, Cavalcante EF, Antunes M, et al. Effects of whey protein supplementation pre- or post-resistance training on muscle mass, muscular strength, and functional capacity in pre-conditioned older women: a randomized clinical trial. Nutrients. 2018. 10: 563. https://doi.org/10.3390/nu10050563

Nunes PR, Barcelos LC, Oliveira AA, Furlanetto Júnior R, Martins FM, Orsatti CL, et al. Effect of resistance training on muscular strength and indicators of abdominal adiposity, metabolic risk, and inflammation in postmenopausal women: controlled and randomized clinical trial of efficacy of training volume. Age. 2016. 38:40. https://doi.org/10.1007/s11357-016-9901-6 
Oh SU, Park SH, Park H. Effects of twisting training on middleaged normal weight obese women. JKSLES. 2018. 25:827-838.

Orsatti FL, Maestá N, de Oliveira EP, Nahas Neto J, Burini RC, Nunes PRP, et al. Adding soy protein to milk enhances the effect of resistance training on muscle strength in postmenopausal women. J Diet Suppl. 2018. 15:140-152.

Öztürk ZA, Türkbeyler İH, Abiyev A, Kul S, Edizer B, Yakaryılmaz FD, et al. Health-related quality of life and fall risk associated with age-related body composition changes; sarcopenia, obesity and sarcopenic obesity. Intern Med J. 2018. 48:973-981.

Pacifico J, Geerlings MAJ, Reijnierse EM, Phassouliotis C, Lim WK, Maier AB. Prevalence of sarcopenia as a comorbid disease: a systematic review and meta-analysis. Exp Gerontol. 2020. 131:110801. https://doi.org/10.1016/j.exger.2019.110801

Papadopoulou SK. Sarcopenia: a contemporary health problem among older adult populations. Nutrients. 2020. 12:1293. https://doi.org/10.3390/nu12051293

Peake J, Della Gatta P, Cameron-Smith D. Aging and its effects on inflammation in skeletal muscle at rest and following exerciseinduced muscle injury. Am J Physiol Regul Integr Comp Physiol. 2010. 298:R1485-R1495.

Ring-Dimitriou S, Steinbacher P, von Duvillard SP, Kaessmann H, Müller E, Sänger AM. Exercise modality and physical fitness in perimenopausal women. Eur J Appl Physiol. 2009. 105:739-
747.

Rosenberg IH. Sarcopenia: origins and clinical relevance. Clin Geriatr Med. 2011. 27:337-339.

Rosenberg IH. Summary comments. Am J Clin Nutr. 1989. 50: 1231-1233.

Sammarco R, Marra M, Di Guglielmo ML, Naccarato M, Contaldo F, Poggiogalle E, et al. Evaluation of hypocaloric diet with protein supplementation in middle-aged sarcopenic obese women: a pilot study. Obes Facts. 2017. 10:160-167.

Suebthawinkul C, Panyakhamlerd K, Yotnuengnit P, Suwan A, Chaiyasit N, Taechakraichana N. The effect of vitamin D2 supplementation on muscle strength in early postmenopausal women: a randomized, double-blind, placebo-controlled trial. Climacteric. 2018. 21:491-497.

The Korean Society of Sarcopenia. Sarcopenia. Koonja, Paju, Korea. 2017. p 263-294.

United Nations. World population prospects 2019. 2019 [cited 2019 Sep 10]. Available from: https://population.un.org/wpp/ Download/Standard/Population/

Urban RJ. Growth hormone and testosterone: anabolic effects on muscle. Horm Res Paediatr. 2011. 76 Suppl 1:81-83.

Visser M, Schaap LA. Consequences of sarcopenia. Clin Geriatr Med. 2011. 27:387-399. 